\title{
Intraoperative Care of the Conscious Patient from the Perspective of the Operating Theatre Nurse: A Grounded Theory
}

\author{
Kerstin Brodin, Ove Hellzén, Marie Häggström \\ Department of Nursing Sciences, Mid Sweden University, Sundsvall, Sweden \\ Email: kerstin.brodin@miun.se, marie.haggstrom@miun.se
}

How to cite this paper: Brodin, K., Hellzén, O. and Häggström, M. (2017) Intraoperative Care of the Conscious Patient from the Perspective of the Operating Theatre Nurse: A Grounded Theory. Open Journal of Nursing, 7, 1086-1099.

https://doi.org/10.4236/ojn.2017.79079

Received: September 4, 2017

Accepted: September 23, 2017

Published: September 26, 2017

Copyright $\odot 2017$ by authors and Scientific Research Publishing Inc. This work is licensed under the Creative Commons Attribution International License (CC BY 4.0).

http://creativecommons.org/licenses/by/4.0/

\begin{abstract}
Introduction: Intraoperative care includes a unique knowledge of how to perform a safe and effective surgery procedure. Surgery performed under regional or local anaesthesia allows the patient to remain conscious during the procedure and is rather common in Swedish healthcare today. Aim: The aim was to obtain a deeper understanding of the main concerns of operating theatre nurses (OTN) when caring for conscious patients during the intraoperative phase. Methods: Interviews were conducted with 23 OTNs from five different hospitals in Sweden and analysed according to grounded theory. Findings: The main concern among the OTNs was to take the patient in consideration. The core category "achieve and maintain ethical treatment of patients" in the operating theatre (OT) was a strategy used throughout the intraoperative process. Ethical treatment was described as moral behaviour at different levels and included the team's behaviour, respectful and individualised patientcare, and the working-morale of the professionals. Being vigilant and being flexible were the categories related to the core category. The OTNs constantly assessed where to pay most attention as they balanced between the needs of the patient, the team, and the surgery procedure. Conclusion: It is important that every patient is taken into consideration and that ethical principles are held to the highest standards in the OT. A familiar team can facilitate that. The complex skills that operating theatre nurses develop can be added to explain important competencies within the profession.
\end{abstract}

\section{Keywords}

Conscious Patient, Grounded Theory, Intraoperative Care, Nursing, Operating Theatre Nurse 


\section{Introduction}

In Sweden today, OTNs are registered nurses, providing perioperative nursingcare to surgical patients, which requires unique knowledge and a highly developed set of skills [1]. Perioperative nursing care is provided at the time close to the surgery [2]. The intraoperative phase, which is a part of the perioperative care, starts when the patient arrives in the operating theatre (OT) and ends when he/she is transferred to the postoperative ward. The environment in the OT is highly technological, and time pressure to meet productivity requirements interact with respect for the patient [3].

The nature of medical- and nursing-care often leaves an individual's body exposed to the eyes, hands, assessments, and comments of others [4]. Different levels of anxiety have been reported in patients undergoing surgery, the causes of which may be the fear of pain and discomfort, but also the loss of control, altered body image, and concerns about diagnosis [5]. While any type of surgical procedure, regardless of the method of anaesthesia, can be anxiety provoking for patients, the choice of anaesthesia will primarily depend on the extent of the surgery being performed [6].

General anaesthesia is a reversible state of complete unconsciousness [7]. Using local or regional anaesthesia allows the patient remain conscious during the surgery [6]. This should not to be confused with awareness during general anaesthesia, which is a consequence of some sort of inadequate anaesthesia technique [8]. As a result of anaesthetic and surgical development, more complex procedures are performed under local or regional anaesthesia, which allows for a patient to be conscious throughout the intraoperative phase, fully aware of both their care environment and treatment. Although it is anticipated that the patient will remain awake during the procedure, the patient may require conscious sedation, which means that the patient is sedated, but is still able to respond purposefully to verbal commands, either alone or accompanied by light tactile stimulation [7]. According to Hankela and Kiikkala [9] the perioperative care expectations and perceptions of conscious patients are different than those of general anaesthesia patients. Being awake during a surgery process has been described as a threat against both the body and the ego [10] and this stress that occurs in the awake patient could alter intraoperative care conditions.

OTNs generally describe their role as being there for the patient and that the patient's wellbeing and safety is their responsibility [11] [12]. The fact that OTNs operate behind closed doors means that the value of their work might has been based on their performance in relation to the surgeon [13] [14].

The Swedish Society of Nursing [15] has identified a research gap concerning the intraoperative experience of patients during local or regional anaesthesia. Previous research has primarily described the experiences and perspectives of anaesthesia nurses and patients [16] [17] [18]. Therefore, the current study seeks to address this research gap by describing the intraoperative care experiences of OTNs when surgery is performed on conscious patients. 


\section{Aim}

The aim of this study was to obtain a deeper understanding of OTNs main concerns when caring for conscious patients during the intraoperative phase.

\section{Methods}

\subsection{Design}

Grounded theory (GT) was well suited to examine the issues of the current study since the aim was to obtain a deeper knowledge regarding specific areas. In GT, both quantitative and qualitative data can be used, since "all is data" [19]. Specifically, GT is a general inductive method based on a concept-indicator model aimed to generate a new theory that is grounded in data and to present the process occurring in the field of study [20]. The main task of GT is to provide explanatory conceptual names to patterns of human behaviour [19] and to explain how participants address their main concerns [21].

\subsection{Ethical Approval}

The study was approved by the appropriate ethics committee (Dnr 2016-159$31 \mathrm{M}$ ) and then accepted by the chief physicians at the clinics. Written information about the study (i.e. study purpose, procedure, voluntary nature of participation, right to withdraw, and confidentiality of data) was sent out to the operating departments, and nurses in charge forward the information to the OTNs and invited them to participate. Prior to data collection, all participants provided written informed consent.

\subsection{Context and Participants}

The study was carried out in five different hospitals in Sweden, selected for convenience because of its location. One surgery department was in a university hospital, located in metropolitan area. The other, in regional hospitals, was located in middle-sized cities. One hospital's surgery department were specialized at upper limb orthopaedics and another only performed eye surgery. The other hospitals' surgery departments daily performed a mix of different kind of surgery, for example; urological, orthopaedic, gynaecological (Table 1). Inclusion criteria for the participants, was that they worked in operating departments as registered OTNs, all with a minimum of one year experience of profession and experience of any characteristic of surgery when the patient is conscious. A total of 23 OTNs participated (22 female; Table 1). Participants described the context for their work as being a part of an OT-team, which included the anaesthesia nurse, the circulating nurse (who assisted the OTN with material and documentation), an anaesthetist, the surgeon, and the OTN (Table 1). Variation existed between hospitals which professionals were generally included in the team (Table 1). In hospitals 1 - 3, the anaesthesia nurse, described as responsible for bringing the patient from the preoperative ward to the OT, often remained in sight of the patient throughout the intraoperative process. In hospitals 4 - 5, it 
Table 1. Overview of: Hospitals' surgery departments' clinical characteristics (M-Mixed surgery, O-Orthopaedic upper limb surgery, E-Eye surgery) and team-members that generally were included in the OT during surgery utilizing local or regional anaesthesia in the different hospitals (X-Always-irrespective of anaesthesia method, $\mathrm{XO}-$ Sometimesdepending on anaesthesia method). Total number of participants according to hospitals.

\begin{tabular}{cccccc}
\hline $\begin{array}{c}\text { Professions/clinical } \\
\text { characteristic/total number } \\
\text { of participants }\end{array}$ & Hospital 1 & Hospital 2 & Hospital 3 & Hospital 4 & Hospital 5 \\
\hline $\begin{array}{c}\text { Clinical Characteristic } \\
\text { Operating Theatre Nurse }\end{array}$ & $\mathrm{M}$ & $\mathrm{M}$ & $\mathrm{O}$ & $\mathrm{E}$ & $\mathrm{M}$ \\
$\begin{array}{c}\text { [OTN] } \\
\text { Anaesthesia Nurse }\end{array}$ & $\mathrm{X}$ & $\mathrm{X}$ & $\mathrm{X}$ & $\mathrm{XO}$ & $\mathrm{XO}$ \\
$\begin{array}{c}\text { Circulating Nurse } \\
\text { Anaesthetist }\end{array}$ & $\mathrm{X}$ & $\mathrm{X}$ & $\mathrm{X}$ & $\mathrm{X}$ & $\mathrm{X}$ \\
Surgeon & $\mathrm{X}$ & $\mathrm{X}$ & $\mathrm{X}$ & $\mathrm{XO}$ & $\mathrm{XO}$ \\
$\begin{array}{c}\text { Total number of } \\
\text { participants }\end{array}$ & $\mathrm{n} .4$ & $\mathrm{n} .8$ & $\mathrm{n} .8$ & $\mathrm{n} .2$ & $\mathrm{X} .1$ \\
\hline
\end{tabular}

was more common that the OTN accompanied the patient to the OT, as surgery with local anaesthesia was performed more frequently and presences of an anaesthesia nurse was not deemed necessary. The anaesthetist was present in the OT, depending on resources, anaesthetic method, and patient's medical condition. OTN, circulating nurse, and surgeons were represented in all five hospitals.

\subsection{Data Collection and Analysis}

Data was collected from focus group and individual interviews (Table 2) between September 2016 and March 2017.The interviews were conducted in places chosen by the participants and major part chosed the hospital, near the working places. Five interviews were held at the university area as preferred by some of the participants.

The interviews began with the question "Can you tell me about how it is to work in the operating theatre as an operating theatre nurse when the patient is awake during surgery?" That initial question aimed to collect spontaneous descriptions of what the participants considered as most important aspects of the research area [22]. Followed-up questions, such as "Can you describe that more?" and "Can you expand on that?" were asked during interviews.

Notes were written after each interview to capture ideas and continued as a simultaneous activity through the analysis [23]. The basic goal of notation was to develop ideas with complete freedom [24]. In accordance with GT, data collection and analysis were jointly performed [21] and began with focus-group interviews. The focus-group dynamic was used to generate a rich description and to record a variety of perspectives about research area [24]. Further, constant comparison began after the first interview [23]. When the recorded interviews were transcribed, they were coded in the right-hand margin. The process started with 
Table 2. Overview of data collection and informants.

\begin{tabular}{cccccc}
\hline No. & Interviewer & Interview & $\begin{array}{c}\text { Informants } \\
\text { recruited from }\end{array}$ & $\begin{array}{c}\text { Number/years of } \\
\text { experience as OTN }\end{array}$ & $\begin{array}{c}\text { Interview length } \\
\text { in minutes }\end{array}$ \\
\hline 1 & K.B /M.H & Focus group & Hospital 1 & 4 OTN/8-40 years & 81 \\
2 & K.B/M.H & Focus group & Hospital 2 & 4 OTN/2-21 years & 65 \\
3 & K.B & Focus group & Hospital 3 & 4 OTN/3-30 years & 53 \\
4 & K.B & Focus group & Hospital 3 & 3 OTN /1-11 years & 55 \\
5 & K.B/M.H & Individual & Hospital 2 & 1 OTN/6 years & 65 \\
6 & K.B & Individual & Hospital 2 & 1 OTN/34 years & 70 \\
7 & K.B & Individual & Hospital 2 & 1 OTN/44 years & 42 \\
8 & K.B & Individual & Hospital 2 & 1 OTN/32 & 74 \\
9 & K.B & Individual & Hospital 3 & 1 OTN/40 & 70 \\
10 & K.B & Individual & Hospital 4 & 1 OTN/23 & 63 \\
11 & K.B & Individual & Hospital 4 & 1 OTN/32 & 60 \\
12 & K.B & Individual & Hospital 5 & 1 OTN /35 & 62 \\
\hline
\end{tabular}

open coding, meaning everything was coded, keeping in mind the question "What is really occurring in the data?" [23]. The codes, derived from the text, were then sorted, compared, and renamed several times during the process. These preliminary concepts, main concerns, and core categories, acted as a guide and indicated that individual interviews could add more depth to data. Individual interviews were then conducted (Table 2), still aimed at bringing inductive perspective to the data. While interviewing and analysing the data, ideas of what to ask next arose, and more specific questions for the subsequent interviews were generated (Table 2).

The core category, central for all of the other categories, represents patterns of participant behaviour performed to address the main concern [24]. The main concern can be defined as a chief mover of action in an area of study [21]. As the core category developed, the selective coding began, which was limited to those variables related to the core category [25]. The final step in the analysis process, theoretical coding, can be described as a set of conceptual model of relationships that were found to relate the codes to each other [26]. The analysis process was partly cross-validated by the second and third authors to ensure the first author's experiences of the phenomenon were not biased. Theoretical saturation was assumed when new data did not provide new information to the category or theory [27].

\subsection{Findings}

The main concern among OTNs when a patient is conscious during surgery was to take the patient in consideration (Table 3). The OTNs emphasised the importance of providing each patient with individual treatment, so that they may feel that they have been respectfully cared for, and are the central focus of 
Table 3. Overview of findings.

\begin{tabular}{cc}
\hline \multicolumn{2}{c}{ Main concern: Taking the conscious patient into consideration } \\
\hline Core category: Achieve and maintain high ethical standards in the OT \\
\hline Being vigilant & \multicolumn{1}{c}{ Being flexible } \\
\hline - React to ethical lapses & - Adaptive team communication \\
- Assess where to focus & - Coing on or off stage \\
& Theoretical code: Balancing among needs - patient, team, and safety \\
\hline
\end{tabular}

attention. To address the main concern, participants strove to achieve and maintain ethical treatment of patients in the OT throughout the intraoperative process (Table 3). Ethical treatment was described by the participants as a whole, with the goal of providing the patient an overall positive experience. To achieve and maintain these high ethical standards in the OT, three parts were described as being taken in regard; the patient, the team, and the professional role of the OTN. That all team-members acted professionally and concentrated on their duties, adjusted to the patient's specific needs and focusing on the patient's safety, was explained as important to achieve high ethical standards. Further, this was also explained as working to achieve a safe and smooth surgery, which was believed to be part of the OTN's professional role. This was understood as any ethical lapse treatment, behaviour, or professional-duty could cause disgrace for the participants.

The nursing-care activities, aimed at achieving and maintaining high ethical standards in the OT, are explained in the categories, being vigilant and being flexible (Table 3). The theoretical codes, balancing between needs-patient, team, and safety, relates to these categories. These codes demonstrate the balance sought by OTNs among all of the interpreted needs in the OT, and how they would adapt to address these needs, depending on what they assessed as most pertinent, based on the prevailing circumstances. The overall findings are presented in Table 3.

\subsection{Core Category: Achieve and Maintain High Ethical Standards in the OT}

Achieving and maintaining high ethical standards in the OT was an important skill OTNs demonstrated for taking the needs of the patient in consideration. To achieve and maintain ethical standards, as fundamental to the reduction of risk concerning the core category, was described by the participants like "having eyes in the neck", with the aim of feeling in control over the OT environment. Participants emphasized the importance of being aware of everything happening in the OT, in an effort to interpret various needs as they arose. It was described that they constantly tried to notice any possible difficulties, in an effort to promote an intraoperative phase where the patient was always taken into consideration. This also included being aware of critical phases during the surgery procedure as 
a part of their professional role. Being aware, within the context of facilitating high ethical standards, was to prevent anything or anyone from causing patient discomfort. According to the participants, discomfort could be conceptualized as signs of pain [e.g. feet moving under the surgical covering]. However, this could also be conceptualized as team members using cell phones or computers for personal reasons that shifted focus from the patient and the surgery process. Despite this, risks that shifted focus from the patient were sometimes let to pass. This was done for the reason of not starting an argument in the OT. Instead, the OTNs described feeling like inappropriate behaviour of colleagues required to be even more aware of the whole, to compensate for the ethical lapses of other team members. Participants with more experiences expressed that they had developed skills to predict critical elements that could endanger ethical standards. This was described as a strength, and that successful attention to the whole process, utilizing correct nursing interventions, was expressed as feeling highly ethical and satisfying.

\subsection{Being Vigilant}

Being vigilant was a way to achieve and maintain ethical standards and is further explained in the subcategories react to ethical lapses and assess where to focus. However, vigilance, according the participants, was to keep a watchful eye, interpret, and react to elements that could have negative effects on the patients' experience, such as difficulties in the surgical process, disrespectful behaviours, and/or inappropriate conversation.

The participants described that they reacted to ethical lapses in sense that they would reprimand non-acceptable behaviours and/or conversation. Avoiding inappropriate elements that the conscious patient could notice was described as especially significant for maintaining ethical standards. The intention was to correct these inappropriate behaviours by either reminding team members about the awake patient, becoming very quiet (i.e. not answering), or by changing the direction of the conversation.

“.... if I see something is going to go wrong or someone says something inappropriate, then I have to react to that, of course..." (OTN, interview 1)

The same reaction was described if a discussion about a patient who was not present occurred (i.e. a telephone call from other wards or between surgeons during a surgery), which was perceived as unethical lapse in maintaining confidentiality. With more work experience in the unit, the OTNs expressed a growing courage to correct errors to achieve and maintain high ethical standards in the OT.

\subsection{Being Flexible}

To achieve and maintain high ethical standards, participants highlighted the importance of being flexible during surgery, taking into account the patient, the team-members, and the surgery process. This concept concerned how they talked, what they said, what they did, and when they did it. They assessed every situation trying to fit in as long as it maintained high ethical standards and en- 
hanced the patient experience. Adapted team communication was explained as communicating clearly, but with the aim of not worrying the patient. This adapted communication was performed both verbally and non-verbally. Nonverbal communication was easier to manage when the team members knew each other. They used the eyes and a kind of sign language to gain each other's attention. It was described by many of the participants as ethical if they could avoid frightening terms like "knife" or "needle" as much as possible, but at least so it did not cause anxiety within the patient. In situations when the participants needed to speak, they tried to express what they needed to say through whispering or by talking it in positive terms, so that the patient should not misunderstand.

“...the conscious patient is so incredibly nervous and responsive to everything and all the little nuances... you can hardly communicate at all without making the patient nervous..." (OTN, interview 10)

Flexibility included being on or off stage was described as adjusting the interaction with the patient. The participants explained that, by getting a picture of the state of the patient they were able to adapt this interaction. The first patient meetings were mostly described as occurring when the patient entered the OT, accompanied by the anaesthesia nurse. This time was described as a short moment to perceive what kind of patient this was, and attempt to gain the patient's trust. When the patient made eye contact, and seemed rather calm, the OTNs sought more interaction than if the patient hardly answered or showed signs of fear.

"In the way that the patient answered, you would get an idea of how nervous the patient was. So, already in the first meeting, you get a picture of how the patient will act on the operating table, and from that, I adapt myself..." (OTN, interview 5)

The OTNs indicated that they sometimes would back off and let the anaesthesia nurse continue undisturbed, so as not to cause the patient more discomfort or anxiety. In situations where the participants perceived it was difficult to get near the patient and make a contact before preoperative disinfection, an assessment about the value of this interaction was performed. It was described that OTNs typically waited for the most appropriate time to "get on stage", depending on how they perceived the patients' needs, the value of contact, time-pressure, and the team's attitude in the OT. The importance of creating a professional relationship with the patient was described, but for ethical reasons, they never seemed to force contact that was not wanted or needed. Being "off stage", taking the patient in consideration was not seen as a problem for OTNs. Participants expressed that a part of achieving high ethical standards in the OT was that all of the team members felt comfortable with the role taken on by the OTNs. From the perspective of the participants, did not matter if their role was passive or active, as long as they perceived their behaviour was best for the patient.

Comprehension of needs was described as a combination of various skills. 
During a surgery-process, there were many different needs that would emerge. The description provided by OTNs of their professional role was advocating for the patient and being responsible for the successful outcome of the surgery process. When a patient undergoes surgery with local or regional anaesthesia, the information provided to the patient was very important. OTNs underlined that things the patient could perceive [e.g. preoperative disinfection, changing the patient's body-position, needle sticks], could never be done without informing the patient first. The participants explained that they provided this information to the patient in a way they deemed necessary for each patient. Participants further described their professional roles as not only insuring that the patient did not maintain a body position that could cause harm, but also preparing the patient for lying in said position so that it did not start to feel uncomfortable soon after. It was also described as understanding the importance of creating appropriate access to the surgery area, promoting a safe surgery process. The participants did not compromise the aseptic or surgical quality, but they expressed the value of patient's needs for comfort. As a part of the comprehension of patient needs, the OTNs determined if the patient liked to talk during surgery, then they tried to find anything that could include the patient in the conversation. They sought to uncover common interests if it brought comfort, reduced anxiety, and helped the patient overall in the foreign environment of the OT. Although the participants described that they were involved in this kind of talking, they only did so when necessary and would not distract the surgeon and/or the safe surgery process.

\subsection{Balancing among Needs-Patient, Team, and Safety}

The theoretical code, balancing among needs-patient, team, and safety, illustrates the importance of knowing where attention should be directed and when, to fulfil the goal of achieving and maintaining high ethical standards in the OT. Even though knowledge of aseptic conditions and of the surgery procedure itself were elements attributed almost exclusively to OTNs, they also saw their mission as being responsible for establishing a respectful and safe situation for their conscious patients. To accomplish this, they tried to interpret the individual needs of the patient and assess how well the other team members responded to these needs. The participants described that they took on the role that was needed from moment to moment, and adapted their behaviour and performance accordingly. Further, they strove for a smooth surgery, which required focus on the surgery process and the surgeon, but also a focus on helping the patients remain calm during the procedure. The balance among all the needs in the OT by the OTNs was about constantly assessing and reassessing to determine where, and how, they would be the most useful.

\section{Discussion}

The aim of this study was to obtain a deeper understanding of the main concern of OTNs when caring for conscious patients during the intraoperative phase. 
The overall analysis showed that this concern was to take the needs of the patient into consideration. Participants in this GT explained that they always endeavoured for an intraoperative phase with high ethical standards, but that this was perceived as even more important when the patient was awake during the surgery. They described that conscious patients needed to be provided consideration throughout the duration of the surgery. The patient was seen as vulnerable and highly sensitive to everything that happened in the OT, a sentiment that has also been suggested by Eriksson [28]. Additionally, OTNs felt empathy with the patient and tried to make the whole surgical experience as positive as possible. The challenging nature of this has been suggested by Marran [5] and, according to the participants in this study, it largely depended on the ethical standards within the OT team. To address this main concern, participants endeavoured to achieve and maintain high ethical standards within the OT. Ethical standards within the OT, as Lindwall and von Post [29] suggested, can be understood as the combination ethics and habitual behaviours, because of the moral virtue that arises through habits. The morality described in this study involves adjusting nursing care to meet the needs of the patient, maintaining respectful behaviours, and promoting a safe surgical environment. The participants described how they strove to achieve high ethical standards within the OT, based on assessed needs, and facilitated by work experiences. A comparable sentiment was suggested by Lindwall and Von Post [29] who described that the method OTNs perform their work is primarily based on knowledge, values, ethics, and morality.

To maintain high ethical standards, OTNs tried to be aware of the whole OT environment. This was also suggested by Kelvered et al. [11], who stated that the intraoperative nursing care style characteristic of OTNs was to be constantly present in every situation. For the OTNs in this study, to be aware of the whole included having control, and reacting to inappropriate/unethical actions that could put the patient or surgical procedure at risk, or could cause discomfort/ suffering. Similar findings have also been discussed in other intraoperative studies, utilizing the term "situation awareness" [30] [31] which is defined as "knowing what is going on".

Knowing fellow members of the surgical team well seemed to be of great value, according to the sentiments of the participants of this, and other studies [32] [33] [34]. Being familiar with the team was expressed in this study as a facilitator to achieve and maintain high ethical standards in the OT, which is in line with the results presented by Lindwall and Von post [29]. This type of familiarity can facilitate non-verbal communication and optimize important elements of collaboration within the team, a sentiment that was also suggested in a study by Sandelin and Gustafson [35]. In the present, as well as other studies [35] [36] [37], familiarity with the team can be understood as contributing to the level of situational awareness perceived by OTNs, and assists in achieving and maintaining high ethical standards as a whole. It can further be suggested as being "prepared for expected and assumed incidents and/or disruptive behaviours" when striving to create a respectful and professional care environment. Lindwall 
et al. [38] describes that habits as acts that are sometimes unethical, but performed regularly by some individuals. The situations described by OTNs in this study can explain the importance of being familiar with the team. In other words, knowing the team can also include knowing their habits, especially their bad habits, thus allowing for OTNs to be prepared to address these issues that can negatively affect high ethical standards in the OT.

The theory, presented as a balance among the needs of all individuals within the OT, can be suggested as a balance between technical and non-technical skills. The non-technical skills, as described in other studies [30] [31] [39], can be seen as the ability to think ahead, trying to imagine everything that can go wrong, and utilizing an understanding the team to primitively address these concerns. The balance between needs related to safety and patients, as explained in this study, are similar to concepts suggested by Buber [40]. Buber [40] differentiated relationships, in which an "I and thou" relationship could be understood as when the OTN saw the conscious patient as a person. In this concept, the relationship between the OTN and the patient is considered one based on equality, with a focus on interaction and reciprocity. However the participants in this GT described that they never took more contact than they assessed that the patient desired, which can be seen as ethically correct according to Buber [40]. The balance also included that OTNs responded to the more technical needs that occurred, as they endeavoured to promote a safe surgery. This made the OTNs to assume another approach. Here the OTNs changed the relationship from a "thou" in to an "it". The "I and it" relationship, according to Buber [40] can be understood as a relationship based on more science, where facts and discussions of "cause and effect" dominates. This was described as necessary in some surgical situations when distance and objectivity was required to perform appropriate medical, surgical, and/or nursing interventions. Buber [40] suggested that these two relationships occur in a continuum, where both are present, but to various degrees.

\section{Methodological Discussion}

GT was well suited to describe the main concern in intraoperative nursing care when the patient is awake. The researchers have very different experiences of intraoperative nursing-care in conscious patients, and these experiences were used to validate the results. In GT, that data should speak for itself, with each category being grounded in data, rather than rising from researcher's preconceptions [28]. The first researcher's experiences within the OT have been taken in consideration, and data was cross-validated by the other two authors.

A GT must demonstrate four criteria; fit, workability, relevance, and modifiability [19]. The theory fits when categories represents the pattern of the data [26]. Relevance is shown when the generated theory explains how the participants resolve the main concern they described as an important issue. Workability has been considered, and participants confirmed that the results correctly explain the reality as they experienced it. This theory could be modified if new data 
alters the circumstances.

Participants were employed at five different hospitals in the central region of Sweden. Even though there were differences in their specific experiences, they seemed mostly to talk about the same sentiments and concerns. Some of the participants were former colleagues of the researcher. This was not seen as a problem however, as many years had passed. Instead, some of the participants found it easier to describe their experiences about the research area when they were familiar with the interviewer. While the current study describe the specific experiences of the participants, the results can be relevant in any context where medical or surgical treatments are performed in team.

\section{Conclusion}

The findings illustrate the importance of a common vision of high ethical standards within a surgical team to ensure that the patient is taken in consideration. This study also reveals how vulnerable ethics can be in an unfamiliar team, both from a technical and non-technical standpoint, and suggests that ethics should be strongly considered, especially when it comes to surgery utilizing local or regional anaesthesia. The OTNs concern about considering the conscious patient, and the skills they develop and apply to address this concern, can be added to further describe the professional competencies of OTNs.

\section{Acknowledgements}

The authors would especially like to thank all the participants that share their thoughts and experiences with us.

\section{Declaration}

The study was approved by the appropriate ethics committee (Dnr 2016-159$31 \mathrm{M})$. The authors declare no conflicts of interest.

\section{References}

[1] Lindwall, L. and Von Post, I. (2009) Continuity Created by Nurses in the Perioperative Dialogue-A Literature Review. Scandinavian Journal of Caring Sciences, 23, 395-401. https://doi.org/10.1111/j.1471-6712.2008.00609.x

[2] Lindwall, L., Von Post, I. and Bergbom, I. (2003) Patients' and Nurses' Experiences of Perioperative Dialogues. Journal of Advanced Nursing, 43, 246-253. https://doi.org/10.1046/j.1365-2648.2003.02707.x

[3] Martinsen, K. (2012) Operationssjuksköterskan och den sårbara patienten-Kropp, sinnesförnimelse och integritetszon. [Operating Theatre Nurse and the Vulnerable Patient-Body, Sense of Mind and Integrity Zone]. In: I DåvØy Myklestul, G.H.I. and Eide Hege, P., Eds., Surgery Healthcare-The Operating Theatre Nurse's Perioperative Nursing Care, Studentlittertur, Lund, 29-45.

[4] Lindwall, L. (2004) Kroppen som bärare av hälsa och lidande. [The Body as a Vessle for Health and Suffering]. Ph.D. Disseration, Åbo Akademi.

[5] Marran, J. (2005) Psychological Needs of Patients in the Peri-Operative Environment. Journal of Operating Department Practice, 2, 10-14. 
[6] Cobbold, A. and Money, T. (2010) Regional Anaesthesia: Back to Basics. The Journal of Perioperative Practice, 20, 288.

[7] Rothrock, J.C. and Alexander, E.L. (2007) Alexander's Care of the Patient in Surgery. 13th Edition, Mosby/Elsevier, St. Louis, 105.

[8] Nunes, R.R., Porto, V.C., Miranda, V.T., de Andrade, N.Q. and Carneiro, L.M.M. (2012) Risk Factor for Intraoperative Awareness. Brazilian Journal of Anesthesiolo$g y$, 62, 365-374. https://doi.org/10.1016/S0034-7094(12)70137-X

[9] Hankela, S. and Kiikkala, I. (1996) Intraoperative Nursing Care as Experienced by Surgical Patients. AORN Journal, 63, 435-442. https://doi.org/10.1016/S0001-2092(06)63231-6

[10] Larsson-Mauleon, A., Palo-Bengtsson, L., Ekman, S.-L. and Mauleon, A.L. (2007) Patients Experiencing Local Anaesthesia and Hip Surgery. Journal of Clinical Nursing, 16, 151-158.

[11] Kelvered, M., Öhlén, J. and Gustafsson, B.Å. (2012) Operating Theatre Nurses’ Experience of Patient-Related, Intraoperative Nursing Care. Scandinavian Journal of Caring Sciences, 26, 449-457. https://doi.org/10.1111/j.1471-6712.2011.00947.x

[12] Blomberg, A.C., Bisholt, B., Nilsson, J. and Lindwall, L. (2015) Making the Invisible Visible-Operating Theatre Nurses' Perceptions of Caring in Perioperative Practice. Scandinavian Journal of Caring Sciences, 29, 361-368. https://doi.org/10.1111/scs.12172

[13] Bull, R. and FitzGerald, M. (2006) Nursing in a Technological Environment: Nursing Care in the Operating Room. International Journal of Nursing Practice, 12, 3-7. https://doi.org/10.1111/j.1440-172X.2006.00542.x

[14] Blegeberg, B., Blomberg, A.-C. and Hedelin, B. (2008) Nurses Conceptions of the Professional Role of Operation Theatre and Psychiatric Nurses. Nordic Journal of Nursing Research, 28, 9-13. https://doi.org/10.1177/010740830802800303

[15] Swedish Society of Nursing (2013) Kunskapsluckor inom omvårdnad en första inventering (Internet) Knowledge Gap in Nursing Sciense-An Initial Inventory. https://www.swenurse.se/globalassets/01-svensk-sjukskoterskeforening/publikation er-svensk-sjukskoterskeforening/forskning-och-utveckling-publikationer/kunskapsl uckor.inom.ovardnad_2013.pdf

[16] Caddick, J., Jawad, S., Southern, S. and Majumder, S. (2012) The Power of Words: Sources of Anxiety in Patients Undergoing Local Anaesthetic Plastic Surgery. The Annals of the Royal College of Surgeons of England, 94, 94-98. https://doi.org/10.1308/003588412X13171221501267

[17] Karlsson, A.-C., Ekebergh, M., Larsson Mauléon, A. and Almerud Österberg, S. (2013) Patient-Nurse Anesthetist Interaction during Regional Anesthesia and Surgery Based on Video Recordings. Journal of PeriAnesthesia Nursing, 28, 260-270.

[18] Karlsson, A.-C., Ekebergh, M., Mauléon, A.L. and Österberg, S.A. (2012) Is That My Leg? Patients' Experiences of Being Awake during Regional Anesthesia and Surgery. Journal of PeriAnesthesia Nursing, 27, 155-164.

[19] Glaser, B.G. (2008) Doing Quantitative Grounded Theory. Sociology Press, Mill Valley.

[20] Glaser, B.G. (1999) The Future of Grounded Theory. Qualitative Health Research, 19, 836-845. https://doi.org/10.1177/104973299129122199

[21] Glaser, B.G. (2001) The Grounded Theory Perspective: Conceptualization Contrasted with Description. Sociology Press, Mill Valley.

[22] Kvale, S. (2009) Den kvalitativa forskningsintervjun (The Qualitative Research In- 
terview). 2th Edition, Studentlitteratur, Lund.

[23] Glaser, B.G. (1967) The Discovery of Grounded Theory: Strategies for Qualitative Research. Aldine de Gruyter, New York.

[24] Krueger, R.A. (2000) Focus Groups: A Practical Guide for Applied Research. 3th Edition, Sage Publications, Thousand Oaks.

[25] Glaser, B.G. (1978) Theoretical Sensitivity: Advances in the Methodology of Grounded Theory. Sociology Press, Mill Valley.

[26] Glaser, B.G. (1992) Basics of Grounded Theory Analysis: Emergence vs. Forcing. Sociology Press, Mill Valley.

[27] Hallberg, L.R.M. (2006) The Core Category of Grounded Theory: Making Constant Comparisons. International Journal of Qualitative Studies on Health and Well-Being, 1, 141-148.

[28] Eriksson, K. (2002) Caring Science in a New Key. Nursing Science Quarterly, 15, 61. https://doi.org/10.1177/089431840201500110

[29] Lindwall, L. and von Post, I. (2008) Habits in Perioperative Nursing Culture. Nursing Ethics, 15, 678-681. https://doi.org/10.1177/0969733008092875

[30] Mitchell, L., Flin, R., Yule, S., Mitchell, J., Coutts, K. and Youngson, G. (2011) Thinking Ahead of the Surgeon. An Interview Study to Identify Scrub Nurses' Non-Technical Skills. International Journal of Nursing Studies, 48, 818-828.

[31] Mitchell, L. and Flin, R. (2008) Non-Technical Skills of the Operating Theatre Scrub Nurse: Literature Review. Journal of Advanced Nursing, 15-24. https://doi.org/10.1111/j.1365-2648.2008.04695.x

[32] Gillespie, B.M., Chaboyer, W., Longbottom, P. and Wallis, M. (2010) The Impact of Organisational and Individual Factors on Team Communication in Surgery: A Qualitative Study. International Journal of Nursing Studies, 47, 732-741.

[33] Alfredsdottir, H. and Bjornsdottir, K. (2008) Nursing and Patient Safety in the Operating Room. Journal of Advanced Nursing, 61, 29-37.

https://doi.org/10.1111/j.1365-2648.2007.04462.x

[34] Bleakley, A., Allard, J. and Hobbs, A. (2013) "Achieving Ensemble": Communication in Orthopaedic Surgical Teams and the Development of Situation Awareness-An Observational Study Using Live Videotaped Examples. Advances in Health Sciences Education, 18, 33-56. https://doi.org/10.1007/s10459-012-9351-6

[35] Sandelin, A. and Gustafsson, B.Å. (2015) Operating Theatre Nurses' Experiences of Teamwork for Safe Surgery. Nordic Journal of Nursing Research, 35, 179-185. https://doi.org/10.1177/0107408315591337

[36] Cochran, A. and Elder, W.B. (2014) A Model of Disruptive Surgeon Behavior in the Perioperative Environment. Journal of the American College of Surgeons, 219, 390-398.

[37] Higgins, B.L. and Macintosh, J. (2010) Operating Room Nurses' Perceptions of the Effects of Physician-Perpetrated Abuse. International Nursing Review, 57, 321-327. https://doi.org/10.1111/j.1466-7657.2009.00767.x

[38] Lindwall, L., von Post, I. and Eriksson, K. (2007) Caring Perioperative Culture: Its Ethos and Ethic. Journal of Advanced Perioperative Care, 3, 27-34.

[39] Kang, E., Massey, D. and Gillespie, B.M. (2015) Factors That Influence the NonTechnical Skills Performance of Scrub Nurses: A Prospective Study. Journal of Advanced Nursing, 71, 2846-2857. https://doi.org/10.1111/jan.12743

[40] Buber, M. (1994) Jag och du [I and Thou]. 6th Edition, Dualis Förlag AB, Ludvika, (Original Work Published in German in 1923). 
Submit or recommend next manuscript to SCIRP and we will provide best service for you:

Accepting pre-submission inquiries through Email, Facebook, LinkedIn, Twitter, etc. A wide selection of journals (inclusive of 9 subjects, more than 200 journals)

Providing 24-hour high-quality service

User-friendly online submission system

Fair and swift peer-review system

Efficient typesetting and proofreading procedure

Display of the result of downloads and visits, as well as the number of cited articles Maximum dissemination of your research work

Submit your manuscript at: http://papersubmission.scirp.org/

Or contact ojn@scirp.org 